\title{
“FAZENDO O SERVIÇO”: AS MARCAÇÕES COMO RITOS DE INICIAÇÃO MASCULINA DE HUMANOS E NÃO-HUMANOS NA LIDA CAMPERIA
}

\author{
Marília Floôr Kosby ${ }^{1}$
}

Este breve artigo o é um desdobramento do Inventário Nacional de Referências Culturais - Lidas Campeiras na Região de Bagé/RS, e discorre a respeito das marcações, eventos que são referência quase que unânime nas memórias e narrativas sobre sociabilidade na chamada vida campeira, universo de homens, mulheres, animais, paisagem e utensílios envolvidos na pecuária extensiva do pampa sul-rio-grandense.

O INRC - Lidas Campeiras na Região de Bagé/RS visa o levantamento preliminar, e as consecutivas documentação e divulgação de dados bibliográficos e etnográficos sobre as relações envolvidas na produção pecuária no pampa sul-riograndense $^{2}$. Os colaboradores da pesquisa foram homens e mulheres direta e indiretamente ligados à experiência de lida campeira, dentre os quais podemos citar: alambradores, esquiladores, domadores de equinos, tropeiros, peões campeiros, capatazes, peões caseiros, guasqueiros (fazedores de artefatos e utensílios em couro cru), changueiros (fazedores de serviços rurais gerais sem vínculo empregatício), pecuaristas, bem como alguns técnicos tais como médicos veterinários, agrônomos e sindicalistas, além de poetas, escritores e pesquisadores locais.

As "marcações" são festas anuais nas quais ocorrem a castração dos terneiros (bovinos de 0 a 12 meses de idade) que são apartados dos escolhidos para reprodutores, a assinalação (corte de parte da orelha do animal - imagem 9) e marcação, com ferro quente, da marca do proprietário no couro dos terneiros e terneiras. São esses eventos uma celebração do rebanho, da estância e de seu dono, um rito cuja expressividade, não se refere apenas ao volume de gado, mas à possibilidade de atualizar as relações com aquilo que é tido como "tradição" na vida campeira, mais especificamente, na construção da pessoa do campeiro. Comparecem amigos, familiares e vizinhos da propriedade rural, trabalhadores e patrões. Em alguns casos, mulheres participam,

\footnotetext{
${ }^{1}$ Universidade Federal do Rio Grande do Sul, Brasil.

2 A metodologia do Inventário foi formulada pelo Instituto do Patrimônio Histórico e Artístico Nacional, órgão que também financiou a ação, a partir do PAC-Cidades Históricas. A prefeitura de Bagé/RS foi a proponente da pesquisa, executada entre os anos de 2010 e 2013, pela seguinte equipe de antropólogos e historiadores da Universidade Federal de Pelotas: Prof ${ }^{a}$. Flávia Rieth (Coordenadora), Marília Kosby, Liza Bilhalva, Marta Bonow Rodrigues, Pablo Dobke, Daniel Vaz Lima. O trabalho de campo ocorreu em localidades dos munícipios gaúchos de Arroio Grande, Pelotas, Bagé, Hulha Negra, Herval, Aceguá (Brasil e Uruguai), Jaguarão e Piratini.
} 
geralmente acolhendo as famílias convidadas e administrando a festa, na qual a comida principal é o churrasco de carne bovina e/ou ovina (imagens 2 e 3), acompanhado de outros pratos de origem animal, como o sarrabulho, feito à base de sangue e miúdos de ovelha.

Quando os terneiros são colocados, um por um, para dentro da mangueira, os homens mais velhos encenam aos mais jovens como se atira o laço, como se assinala, como se "capa" ou "faz o serviço" (castra). Aos mais novos é permitido tentar pealar, que é laçar o animal pelas mãos para derrubá-los (imagem 6), imobilizar os bichos e comer os testículos destes. No mesmo fogo em que os ferros das marcas aquecem são jogados os testículos recém extraídos dos terneiros, a carne gordurosa e suculenta não chega a assar e é disputada para ser comida ainda quente, acompanhada de cachaça (imagem 14).

Durante o serviço, que é um híbrido de trabalho, brincadeira e espetáculo ${ }^{3}$, debocha-se daqueles que têm pouca habilidade com o laço e não são ágeis nem fortes o suficiente para segurar os animais enquanto estes são castrados, cortados e marcados. Da mesma forma, desdenha-se e fazem-se chacotas dos terneiros fracos, que "não valem a pena" do esforço de serem derrubados e imobilizados. Quanto mais xucro for o terneiro mais potência é atribuída àquele que o conseguir dominar. E as forças que dão vida a essa potência emanam da relação entre o fato de "o bicho não saber a força que tem" e o de o homem saber da força que não tem: as técnicas de manejo bovino chamadas de "tradicionais" no universo da lida campeira são aquelas em que os gestos de contato se dão através das investidas humanas no sentido de perseguir, capturar e controlar os movimentos e deslocamento dos animais, aos quais o porte e o tamanho atribuem maior possibilidade de aniquilar violentamente seu perseguidor.

\footnotetext{
${ }^{3}$ A diretora teatral e pesquisadora Inês Marocco, em sua tese de doutorado Le geste spectaculaire dans la culture gaúcha du Rio Grande do Sul/Brésil (França,1997), apresenta um estudo etnográfico a respeito das técnicas corporais empregadas na lida campeira, partindo da premissa de que o homem gaúcho é espetacular, num olhar da Etnocenologia. Assim, segundo Marocco: "O espetacular, a partir dessa perspectiva, deve ser aqui compreendido como sustentado pelo corpo, isto é, por tudo o que é referente à aparência física, aos gestos de trabalho, aos hábitos de indumentária e de alimentação, ao discurso, que expressam ao mesmo tempo os valores e os símbolos representativos da identidade cultural do gaúcho.”. A dimensão espetacular dos trabalhadores campeiros é colocada em evidência pela autora a partir de uma seleção de comportamentos e valores recorrentes no universo da lida campeira (seja no trabalho, no lazer, nas festas), quais sejam, a masculinidade, a combatividade, a organização e o excesso. Assim, o aspecto da combatividade ficaria mais evidente nas situações de trabalho, "nas quais o gaúcho encontra-se sempre em situação de combate e em contato direto com o animal” (Marocco, s/d).
} 
O animal xucro é aquele que não foi domado - um sinônimo de xucro é bagual. No entanto, se um animal foi domado e mantém características bravias ou pouco dóceis, ele também pode ser chamado de xucro. Pode ser, inclusive ensinado a ser xucro, o que requer algumas técnicas, como um maior afastamento do convívio com humanos para que seja abagualado. Isso geralmente acontece quando se estão preparando animais para rodeios ou atividades semelhantes.

Nos manejos chamados racionais, como é o caso do "Pastoreio Voisin", há o amansamento das vacas. Aqui o campo é dividido em módulos cercados por um único fio de arame eletrificado, para os quais os rebanhos são encaminhados rotativamente, quase que diariamente. Nesses módulos os animais se alimentam de pastagens e, ao defecarem, deixam o esterco como adubo para a próxima leva de pasto - não são utilizados insumos químicos e artificiais, portanto. No sistema de pastoreio Voisin, o cavalo, o laço e o cachorro são deixados de lado, pois o gado é criado de forma mansa, com manobras lentas e com métodos que excluem a presença de qualquer elemento de agressividade, já que o peão utiliza apenas um alicate isolante e um cajado para suspender a cerca. Geralmente, no Voisin lida-se apenas com gado de engorde, comprando-se animais magros, ainda não "terminados", ou seja, ainda sem a cobertura de gordura necessária para que sejam abatidos. A principal queixa dos produtores que optam por pastoreios racionais se refere à ausência de mão-de-obra; segundo um produtor de Bagé/RS, isso se dá porque "o gaúcho quer correr atrás da vaca, quer ser bruto".

O termo "vaca" geralmente é utilizado para se referir aos bovinos, genericamente, independente do sexo destes animais ("juntar as vacas" ou "a vaca é um bicho coletivo"), diferente de outros universos de pecuária, onde o genérico é "boi". No contexto da marcação ou da lida específica com algum espécime, utilizam-se as denominações "boi" (macho castrado), "touro" (macho "inteiro" ou não castrado), "novilho/a" (bovino/a de 13 a 24 meses), "terneiro" (bovino/a de 0 a 12 meses) e "vaca" (fêmea adulta, com mais de 24 meses).

Nem o uso do laço, do cavalo, ou do relho, enquanto meros contentores da força animal, seriam eficazes se as técnicas de manejo não se pautassem pela capacidade de observação que a vaca possui, mas que deve ser "despertada" sem grandes rompantes. Mesmo em campo aberto, por exemplo, quando se precisa laçar uma vaca, os movimentos do campeiro não devem ser repentinos ou violentos, para evitar que os do 
bicho também o sejam: o laço gira no ar por algumas vezes antes de ser lançado na direção do animal, a atenção deste é captada, mesmo que seja para a fuga; é como se ele fosse de certa forma atraído para essa "performance de caça", para essa "coreografia da prea". E nos casos de vacas mais bravias, aquelas que atacam ao sinal de perigo - ou que são apartadas do rebanho enquanto manejadas, o que deixa um animal de tipo gregário, "mais nervoso" - deve-se desviar, "tirar o cavalo para o lado", ou esconder-se dela. Sobre isso um interlocutor, veterinário de animais de grande porte e criado na lida campeira, no município de Arroio Grande, diz: "tu desvias para o lado, que nem numa tourada, se não ela te passa por cima" ${ }^{4}$.

No contexto de uma marcação, que geralmente ocorre dentro das mangueiras, ou seja, não acontece em campo aberto, se lida com terneiros, sem cavalo, e o laço é utilizado para derrubar o bovino (imagem 5), que será imobilizado pelos próprios corpos dos homens (imagens 7 e 8). Nem estes homens, nem os terneiros, são experientes quanto às técnicas acima descritas, estão se iniciando na lida, o que há é o embate corporal entre homens jovens e bovinos jovens, a inserção de ambos em seus corpos e mundos, sem contenção de movimentos brutos, sem ter grandes espaços para fuga. Mundos e corpos compartilhados entre ambos, pela ingestão dos testículos, pela inserção na mangueira e na captura do pealo: o laço como extensão do braço do homem, a mangueira como condensadora do mundo da lida; a transformação do corpo do animal, a subtração de sua virilidade, como diretamente proporcional à incorporação da mesma pelos homens.

Aos homens maduros cabe a utilização das técnicas mais elaboradas, aprendidas com o tempo - na ordem de aprendizado: pealar, marcar, assinalar, capar. A faca com a qual se capa os terneiros é pequena, muitas vezes passada de geração para geração da família do dono do rebanho, e geralmente feita de prata, pois se diz que este metal evita infecções por bactérias. As marcações costumam acontecer na primavera, já que os rigores do inverno podem ser fatais para os terneiros, que ficam mais vulneráveis enquanto o corte da castração não cicatriza.

\footnotetext{
${ }^{4}$ O cruzamento da relação toureiro/touro com a relação gaúcho/vaca acontece em muitos momentos, principalmente naqueles em que homem e animal se atraem para o "combate" diminuindo ao máximo o intervalo entre seus corpos e fluidos corporais. Toureiro, touro, gaúcho e vaca - estabelecem uma interação espetacular cujas preocupações estéticas são as mesmas da dança, por apresentar características como harmonia, equilíbrio no espaço, organização, precisão e habilidade nos movimentos (Marocco, s/d). Para este estudo não foi realizada pesquisa de campo com touradas, mas a elaboração do mesmo contou com a apresentação de material fotográfico e relato de campo da geógrafa colombiana Isabel Pérez, por ocasião de participação sua numa reunião do Grupo de Pesquisa Espelho Animal (UFRGS). Uma referência importante é também o livro "O espelho da tauromaquia”, de Michel Leiris (2002).
} 
Afora o seu caráter festivo, as marcações permitem perceber aspectos da desigualdade inerentes às relações de trabalho entre peões, patrões a animais: o relato de um peão aposentado, negro e descendente de trabalhadores campeiros escravizados, conta que em algumas estâncias os empregados não podiam usar laço para derrubar os terneiros durante as marcações, devendo agarrar os animais "à unha". Assim, evitar-seia o risco de algum terneiro se fraturar, o que causaria mais prejuízo do que o mesmo ferimento em algum peão. Interlocutor do INRC-Lidas campeiras na região de Bagé/RS, um estancieiro de família pecuarista tradicional, criadora de gado desde primórdios do século XIX, na região de Arroio Grande, sudeste do Rio Grande do Sul, diz que desde as gerações mais antigas "sempre se preferiu o negro para a lida campeira, porque é um serviço muito bruto". A fala do estancieiro relaciona "o negro" com sujeitos submetidos a trabalhos servis e de grande risco para a integridade física, o que não afasta muito essa noção das condições atribuídas à mão-de-obra escravizada.

Embora atualize relações para aqueles homens cujo manejo com os bovinos é um eixo fundamental na sua formação, a grande maioria dos participantes da marcação já não reside mais no campo, nem tem contato tão cotidiano com os rebanhos - o que não diminui a frequência das marcações, ao contrário, demarca seu estatuto de ritual em que as performances reforçam a valentia, a destreza e a força corporal investidas no embate entre homens e terneiros. Na mesma direção, enfraquece-se o sentido utilitário de marcar o rebanho para assegurar a propriedade da terra e dos animais, visto o fracionamento das propriedades e o cercamento das mesmas. Técnicas como a utilização de brete e o tronco para imobilizar o animal, a marcação com queimadura por nitrogênio ou o aquecimento das marcas com fogareiro a gás, a castração química ou com burdizzo $0^{5}$, cumprem os intentos pragmáticos que a produção pecuária exige, mas parecem, por outro lado, aumentar a ênfase de eventos como marcações e rodeios, onde a lida corporal com os animais é o principal agenciador dos sentidos e conceitos. Tais eventos cada vez mais atualizam seu caráter festivo e ritual, mobilizando principalmente jovens dos centros e periferias urbanas, com origem campeira ou não, que fazem dos jogos entre o seus corpos e os dos animais lugares de vivência da relação transespecífica do que pode vir a ser "ser macho" (imagem 16). A yerra, como também a marcação é

\footnotetext{
${ }^{5}$ Espécie de alicate sem fio, com o qual se faz um tipo de castração não cirúrgica em machos. O burdizzo é um emasculador que danifica o cordão espermático, ao apertá-lo, fazendo com que cesse a passagem de sangue e nutrientes para o escroto, que acaba por cair com o passar do tempo.
} 
chamada próximo à fronteira entre Brasil e Uruguai $^{6}$, encerra, portanto, rituais de iniciação de homens e animais na vida campeira, e é assim abordada pelo INRC - Lidas campeiras na região de Bagé/RS.

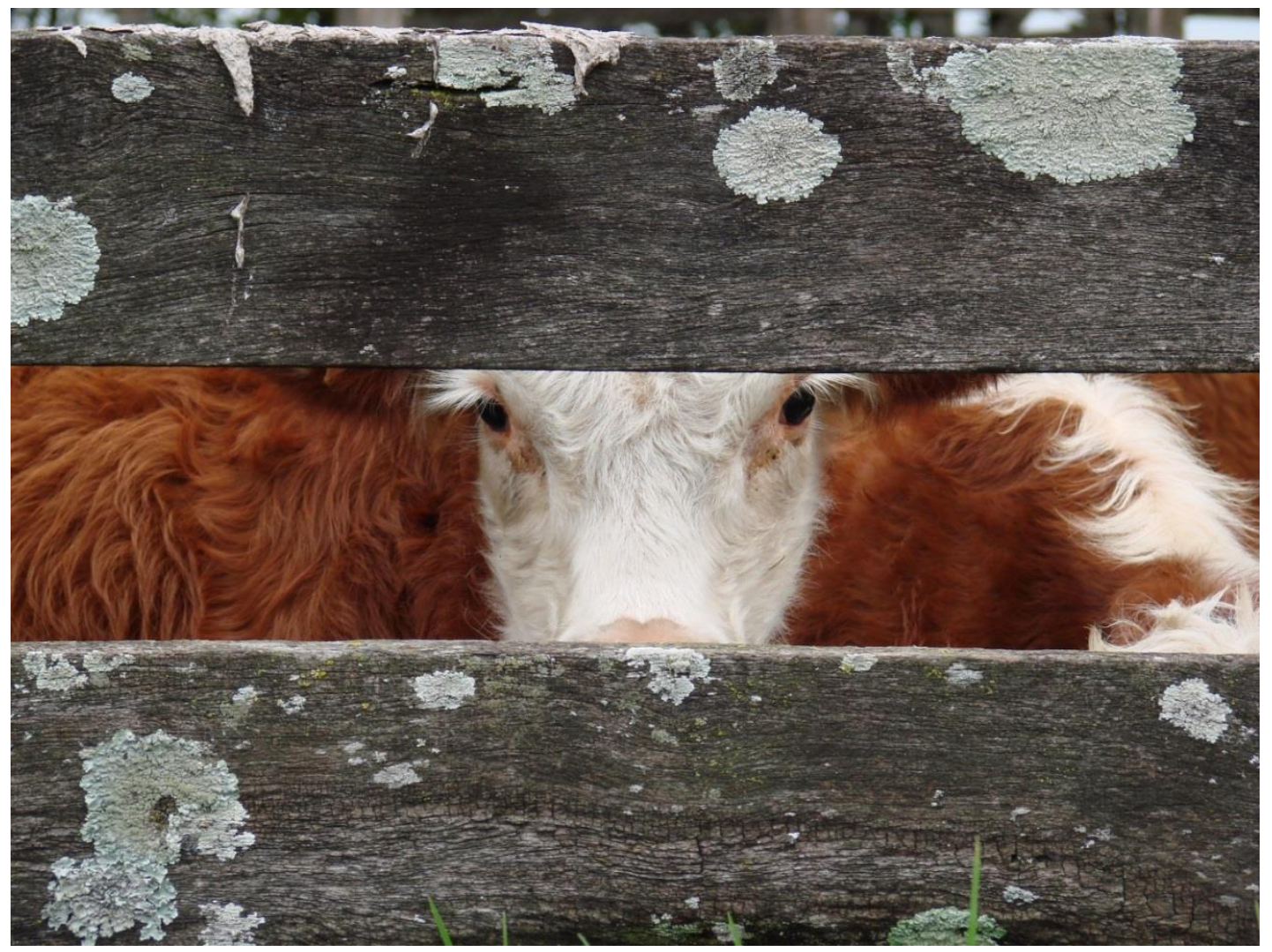

Imagem 1: Terneiros nas mangueiras. Foto de Marília Kosby. Acervo do INRC-Lidas Campeiras na Região de Bagé/RS.

\footnotetext{
${ }^{6}$ Segundo o músico e pesquisador Demétrio Xavier, a denominação "ferra" como designadora dos eventos de marcação do gado bovino é utilizada no norte do Brasil e em Portugal.
} 


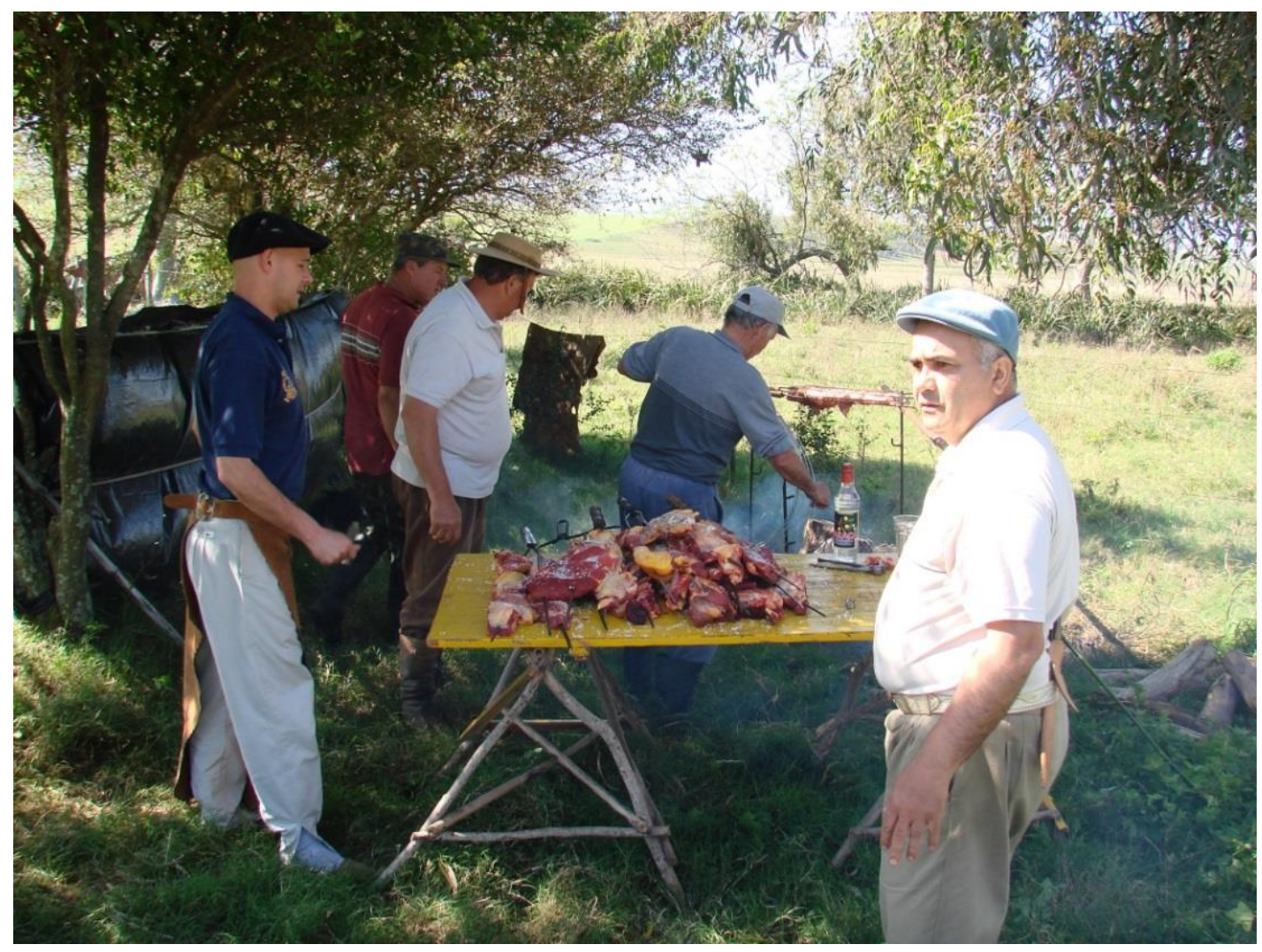

Imagem 2: Início dos preparativos do churrasco, antes de começar a marcação. Foto de Marília Kosby. Acervo do INRC-Lidas Campeiras na Região de Bagé/RS.

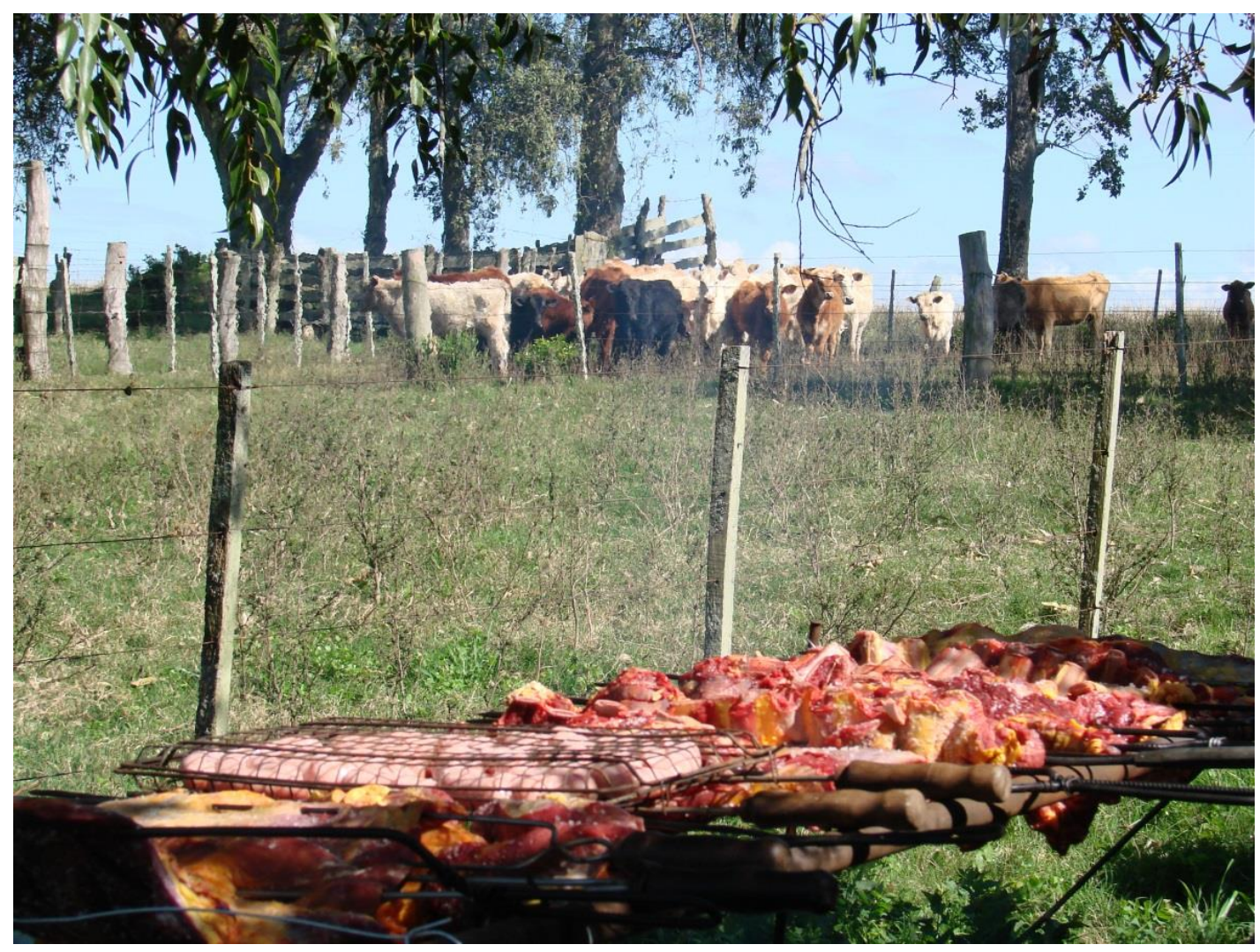

Imagem 3: Terneiros que serão marcados, ao fundo. Churrasco que é servido na festa. Foto de Marília Kosby. Acervo do INRC-Lidas Campeiras na Região de Bagé/RS.

Iluminuras, Porto Alegre, v. 17, n. 42, p. 564-578, ago/dez, 2016. 


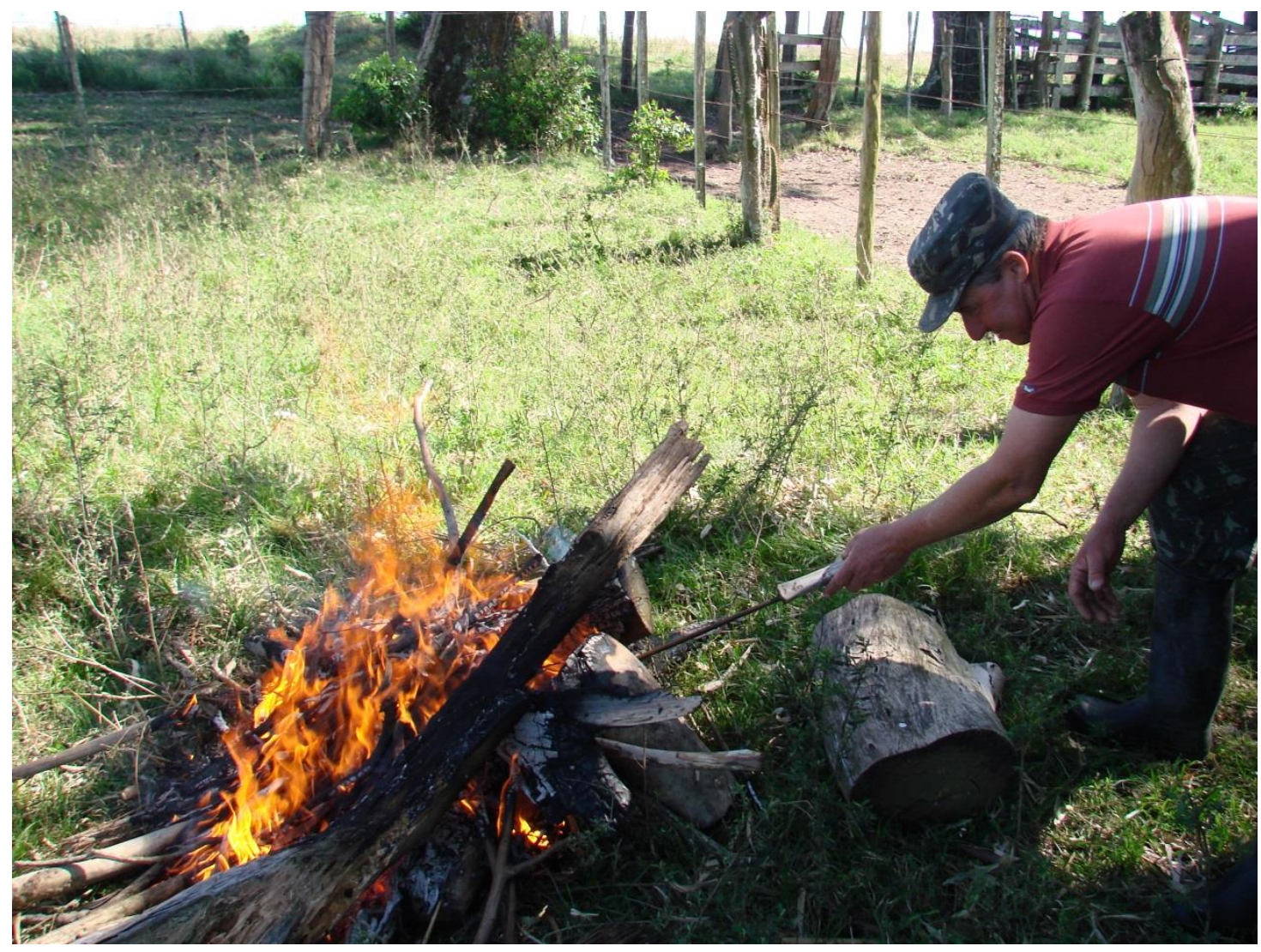

Imagem 4: Aquecimento das marcas no fogo de chão. Foto de Marília Kosby. Acervo do INRC-Lidas Campeiras na Região de Bagé/RS.

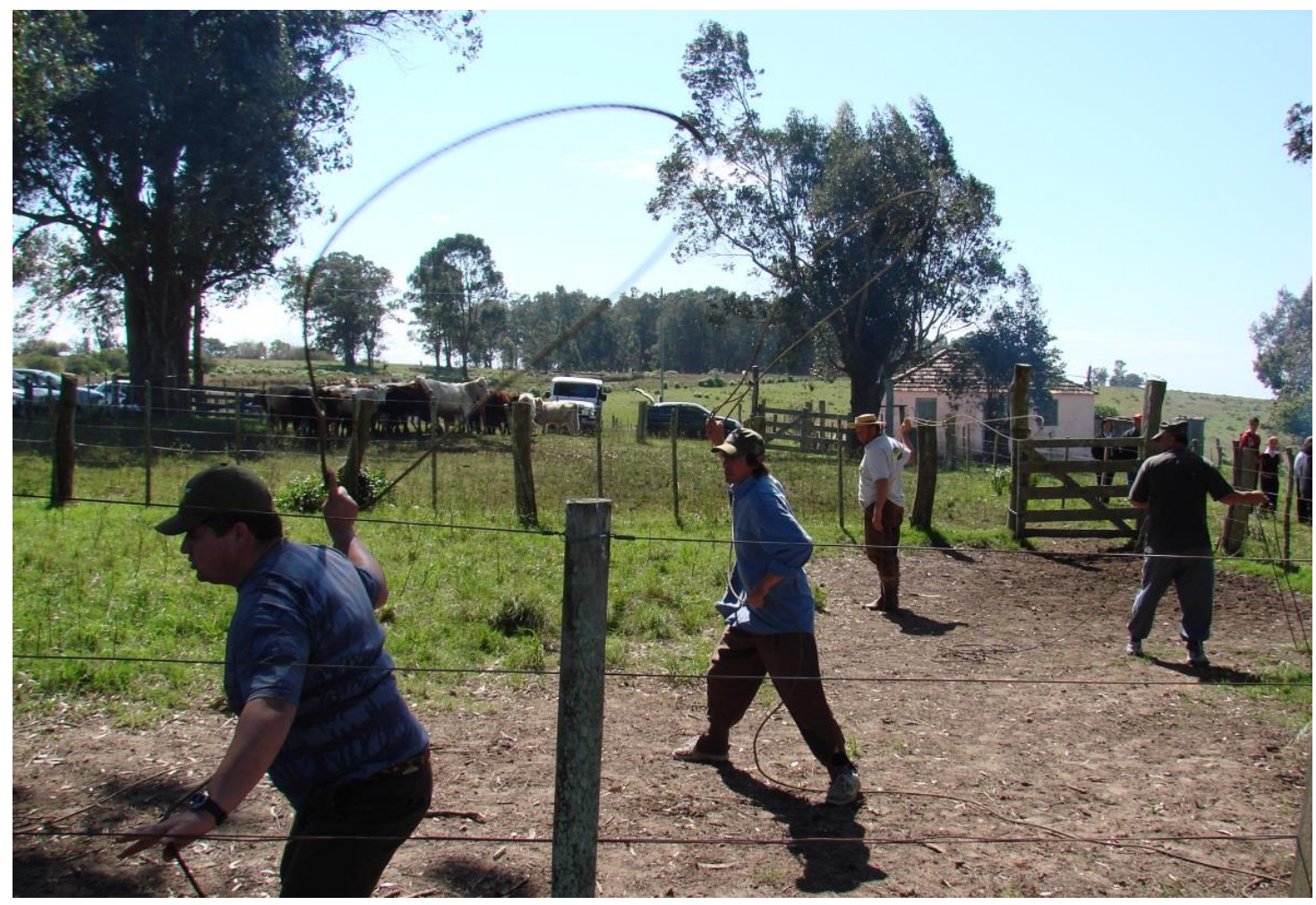

Imagem 5: Homens ensinando os mais jovens a pealar. Foto de Marília Kosby. Acervo do INRC-Lidas Campeiras na Região de Bagé/RS. 


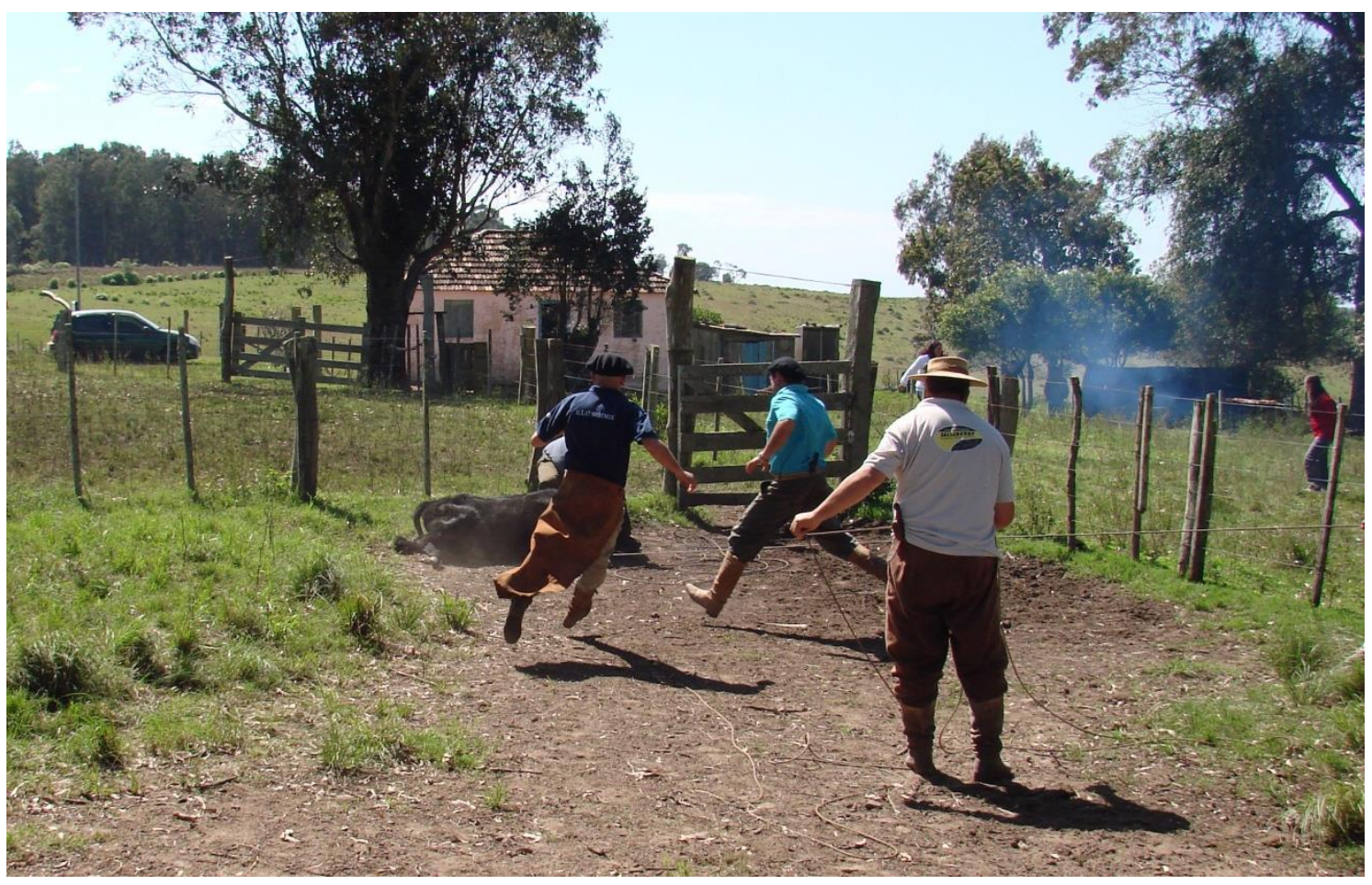

Imagem 6: Guris correndo para imobilizar o terneiro pealado. Foto de Marília Kosby. Acervo do INRCLidas Campeiras na Região de Bagé/RS.

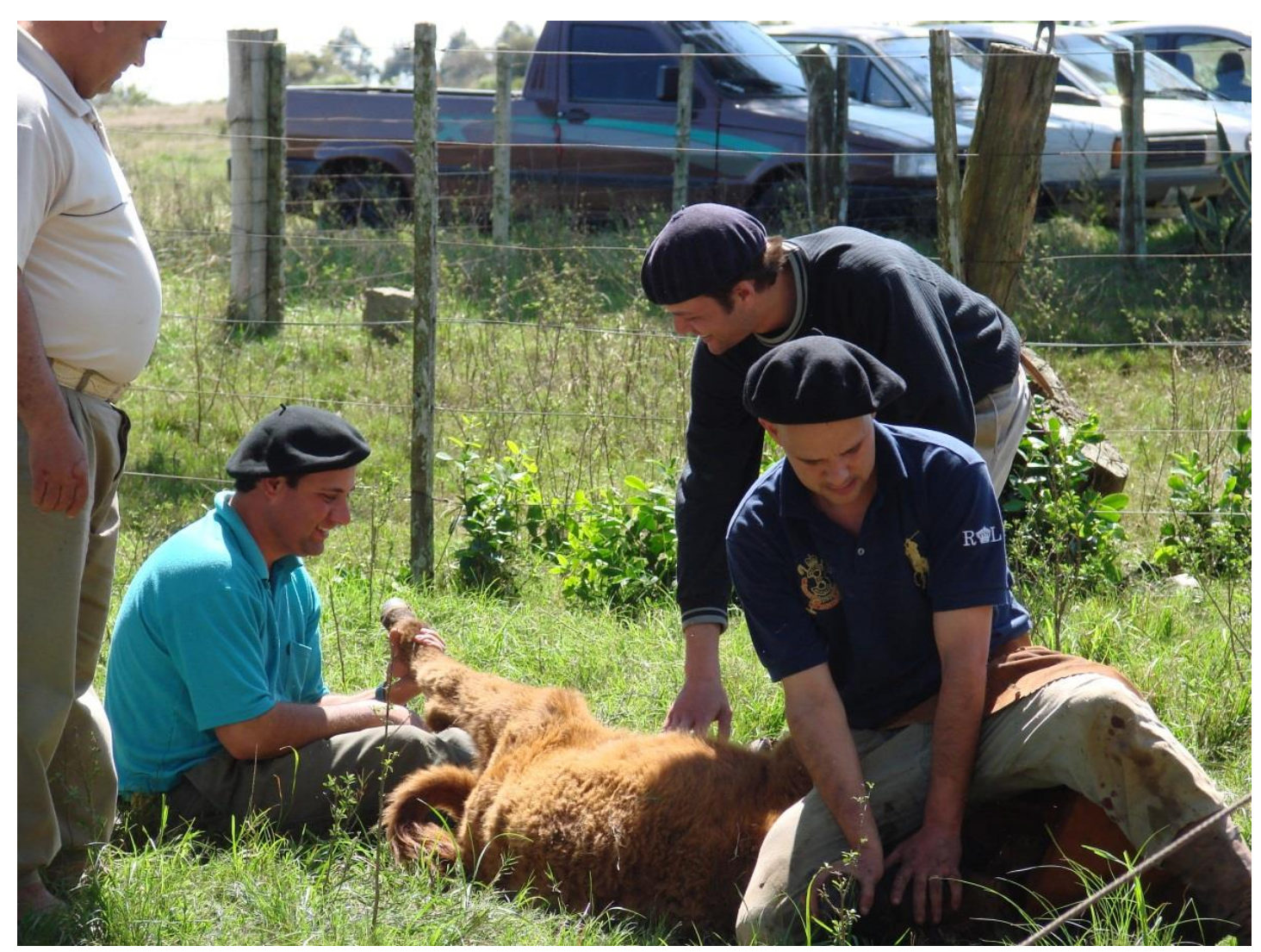

Imagem 7: Guris imobilizam terneiro. Foto de Marília Kosby. Acervo do INRC-Lidas Campeiras na Região de Bagé/RS. 


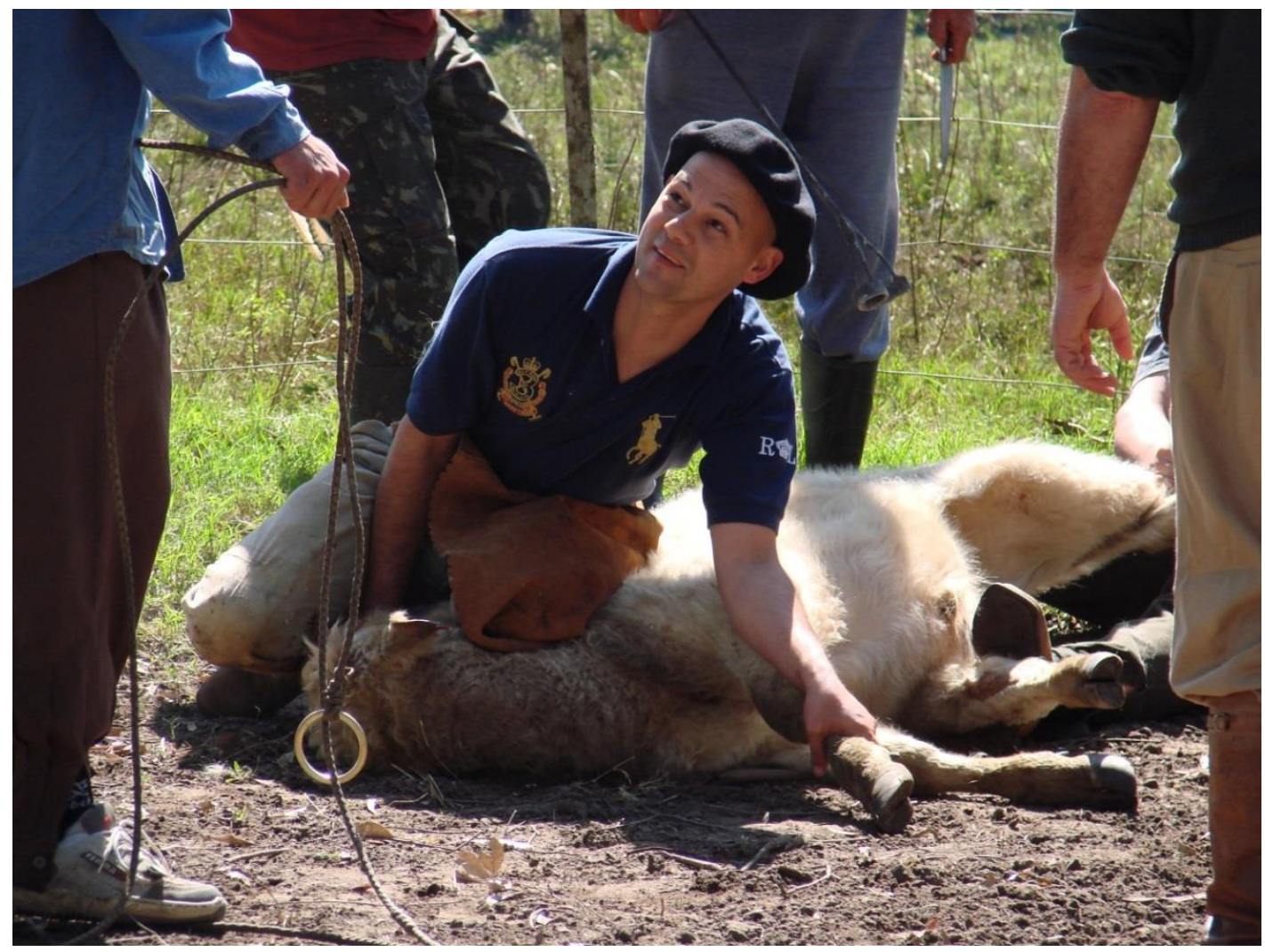

Imagem 8: Imobilização de terneiro para posteriores marcação, assinalação e castração. Foto de Marília Kosby. Acervo do INRC-Lidas Campeiras na Região de Bagé/RS.

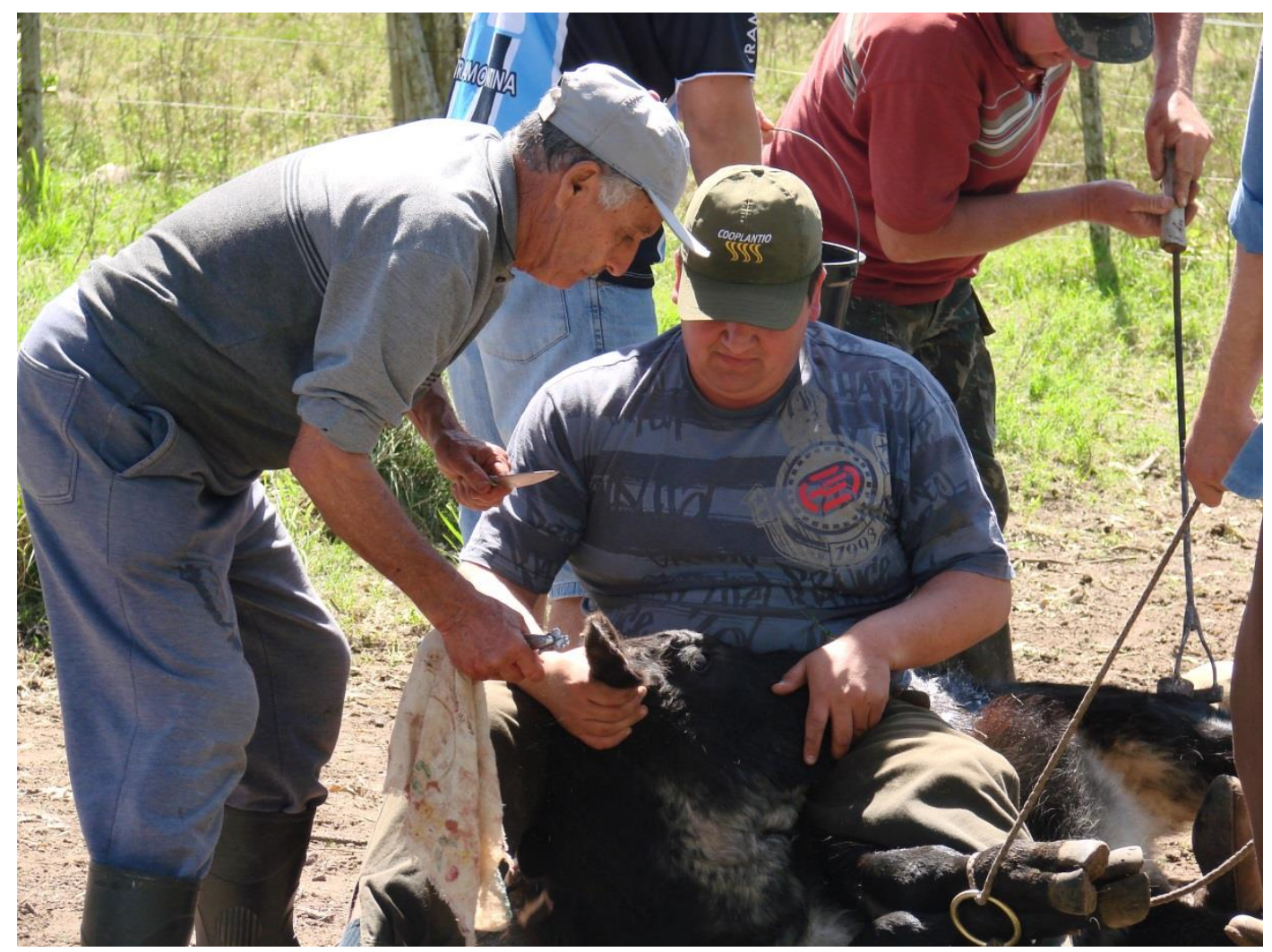

Imagem 9: Assinalação. Foto de Marília Kosby. Acervo do INRC-Lidas Campeiras na Região de Bagé/RS. 


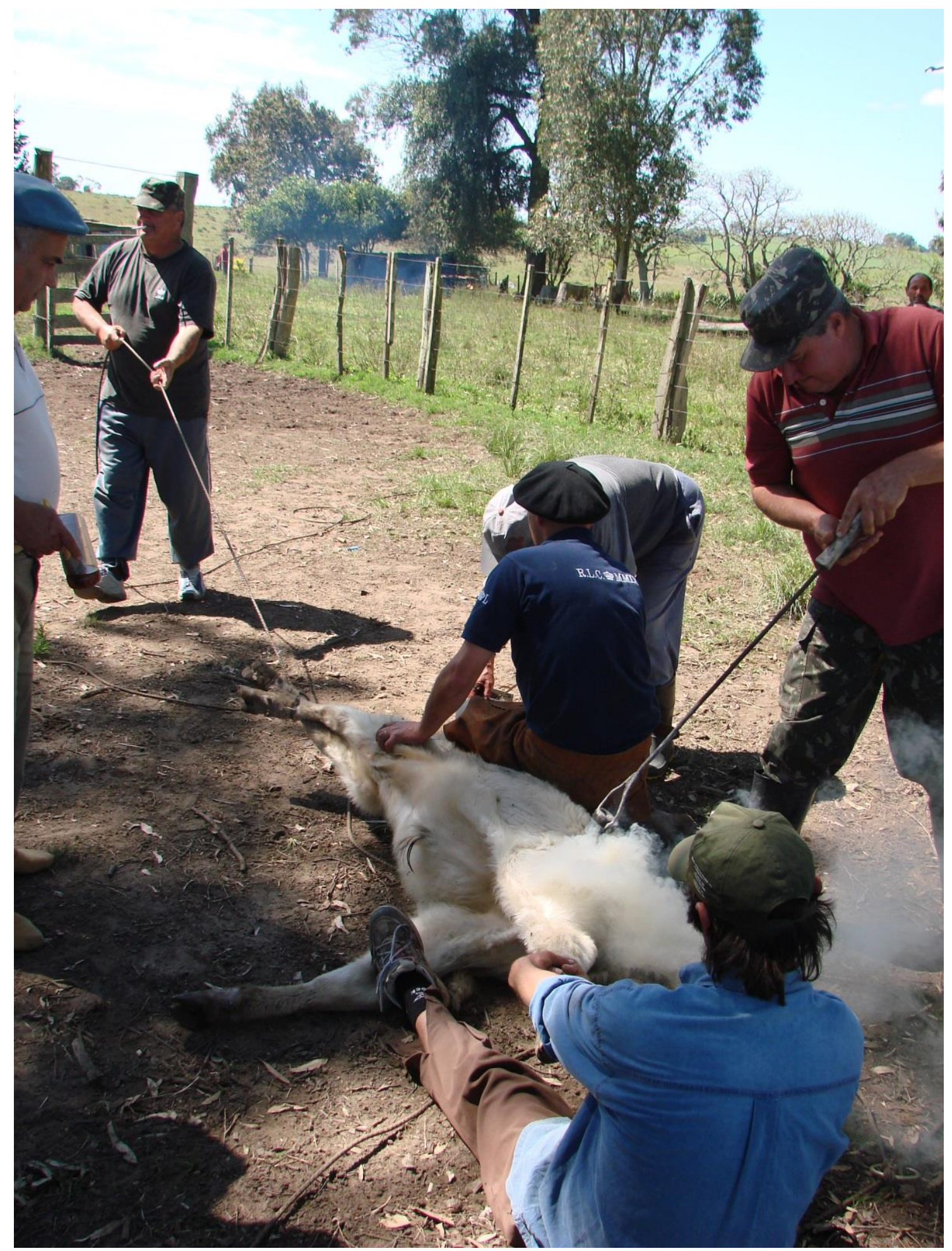

Imagem 10: Marcação. Foto de Marília Kosby. Acervo do INRC-Lidas Campeiras na Região de Bagé/RS. 


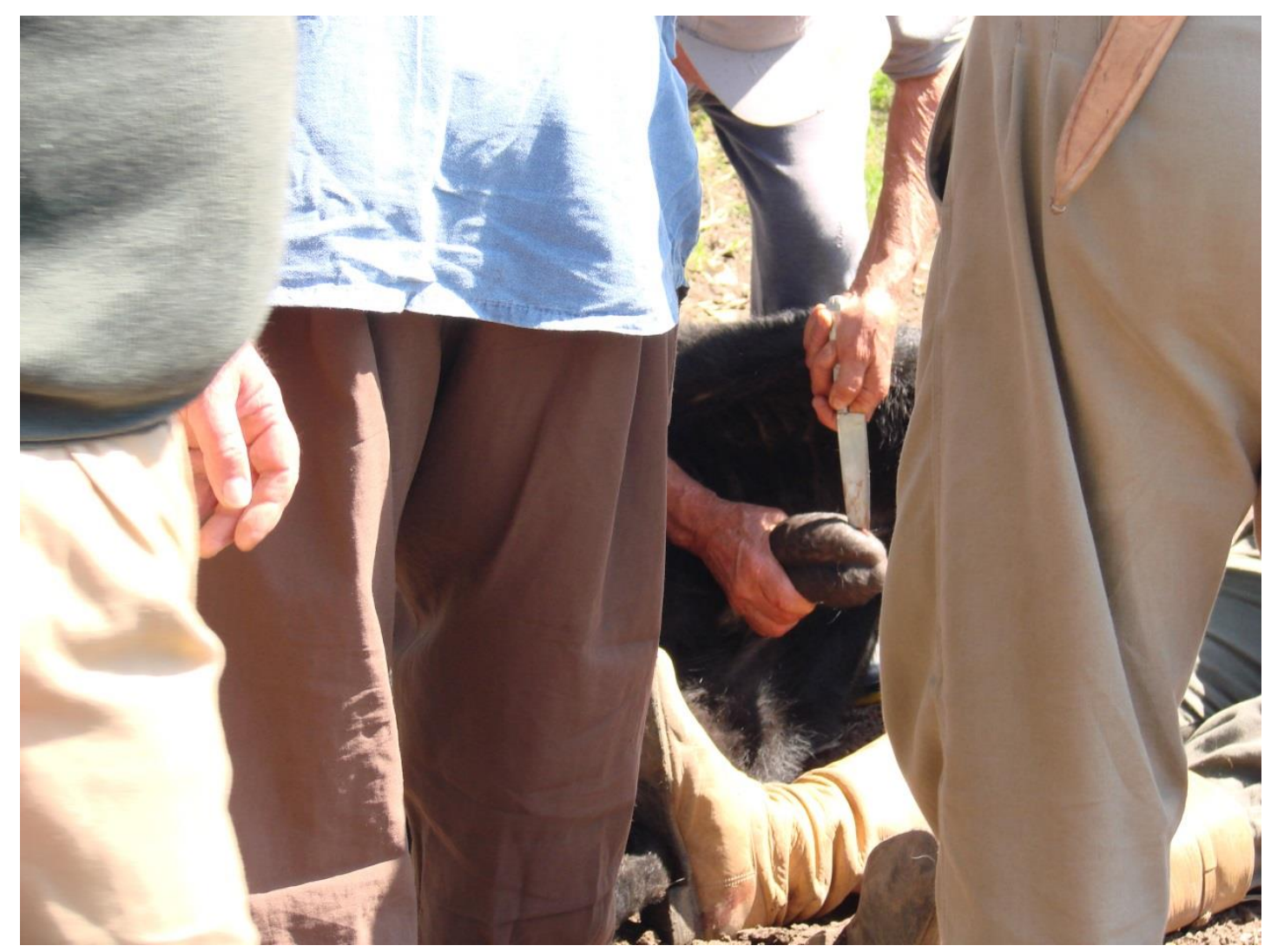

Imagem 11: Capação. Foto de Marília Kosby. Acervo do INRC-Lidas Campeiras na Região de Bagé/RS.

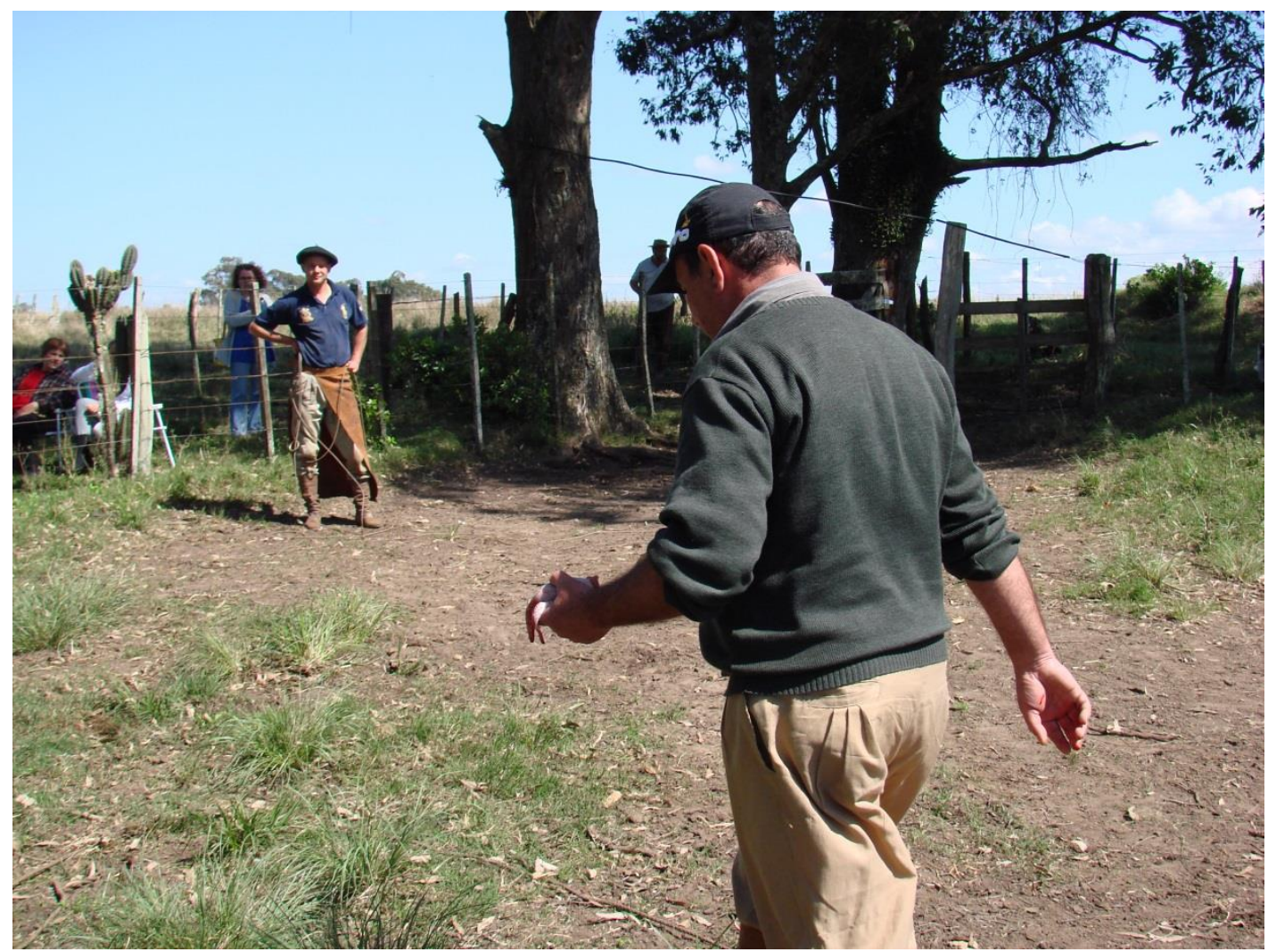

Imagem 12: Homem levando testículos de terneiro para as brasas, onde também aquecem as marcas. Foto de Marília Kosby. Acervo do INRC-Lidas Campeiras na Região de Bagé/RS.

Iluminuras, Porto Alegre, v. 17, n. 42, p. 564-578, ago/dez, 2016. 


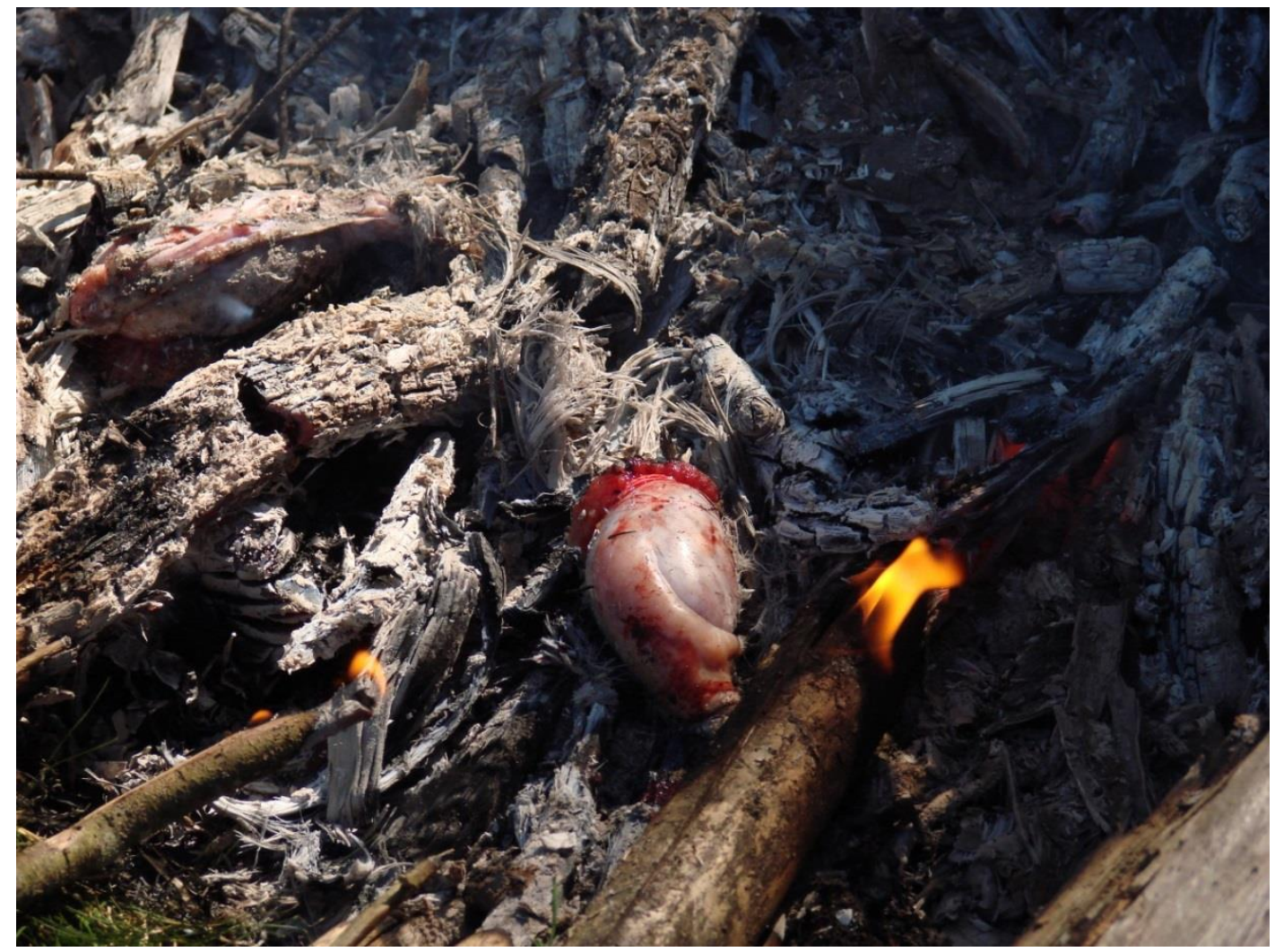

Imagem 13: Testículos nas brasas, antes de serem comidos pelos guris. Foto de Marília Kosby. Acervo do INRC-Lidas Campeiras na Região de Bagé/RS.

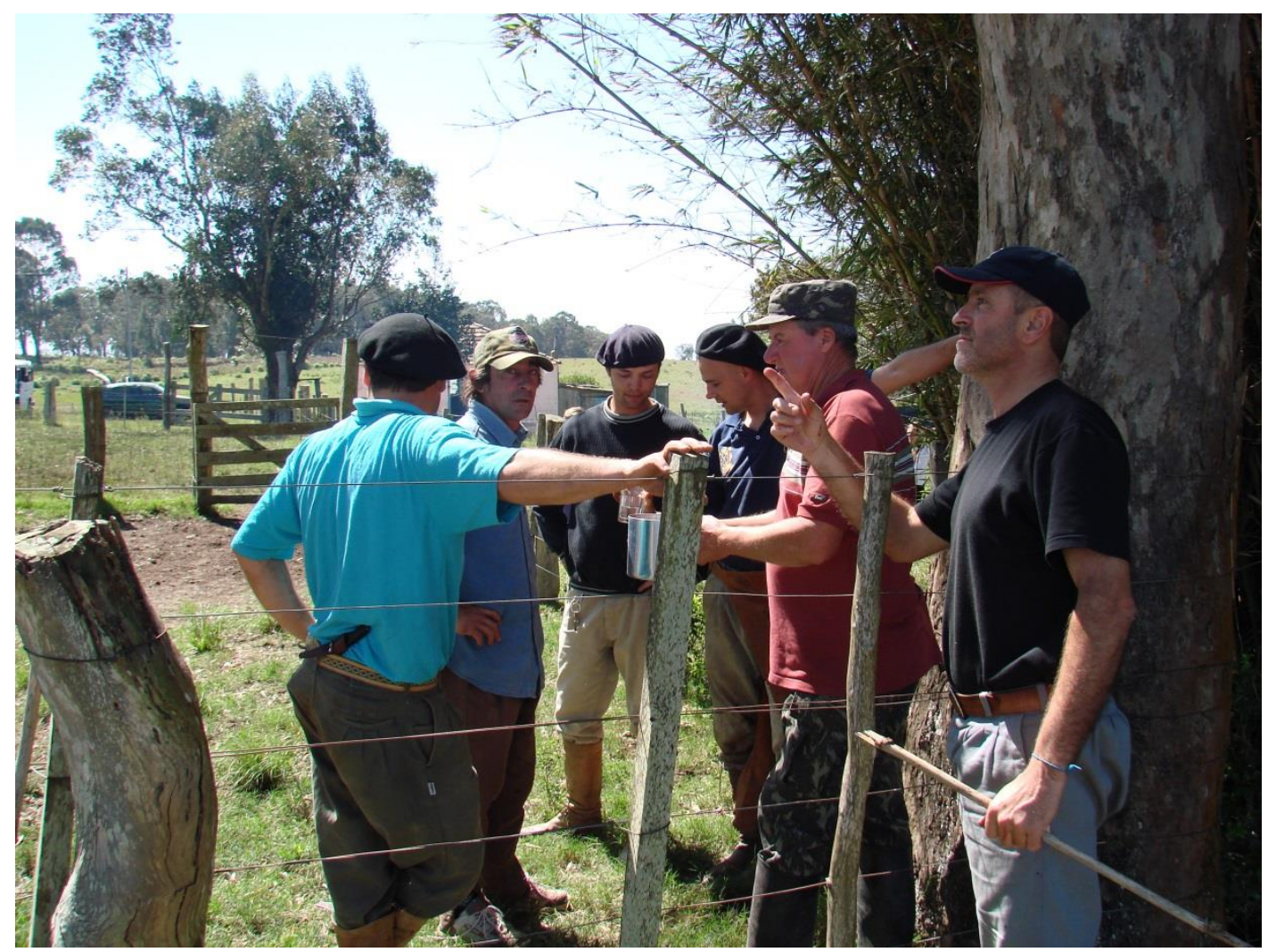

Imagem 14: Comensalidade dos testículos dos terneiros capados, acompanhados de cachaça. Foto de Marília Kosby. Acervo do INRC-Lidas Campeiras na Região de Bagé/RS.

Iluminuras, Porto Alegre, v. 17, n. 42, p. 564-578, ago/dez, 2016. 


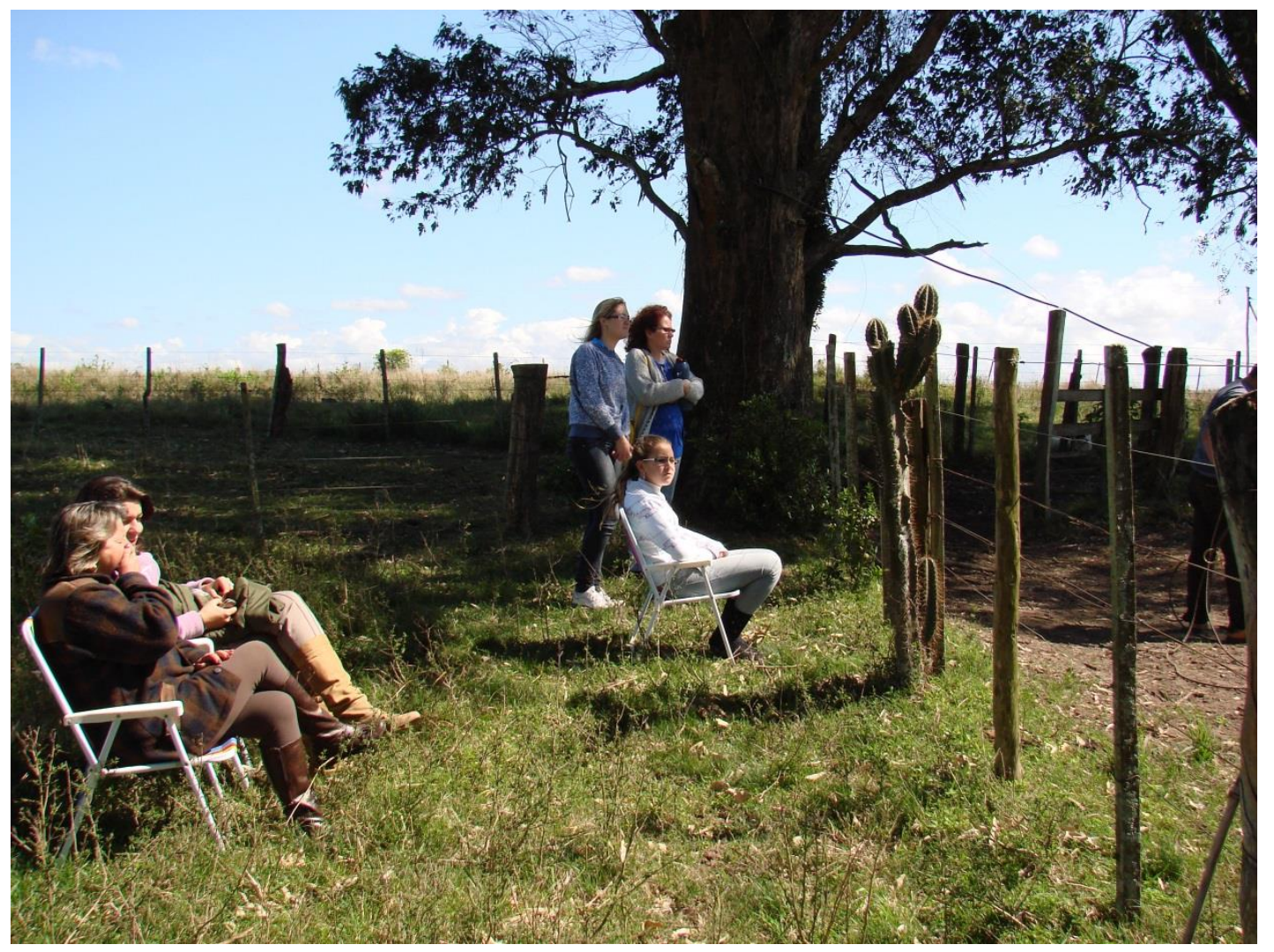

Imagem 15: As mulheres ficam do lado de fora da mangueira. Foto de Marília Kosby. Acervo do INRCLidas Campeiras na Região de Bagé/RS.

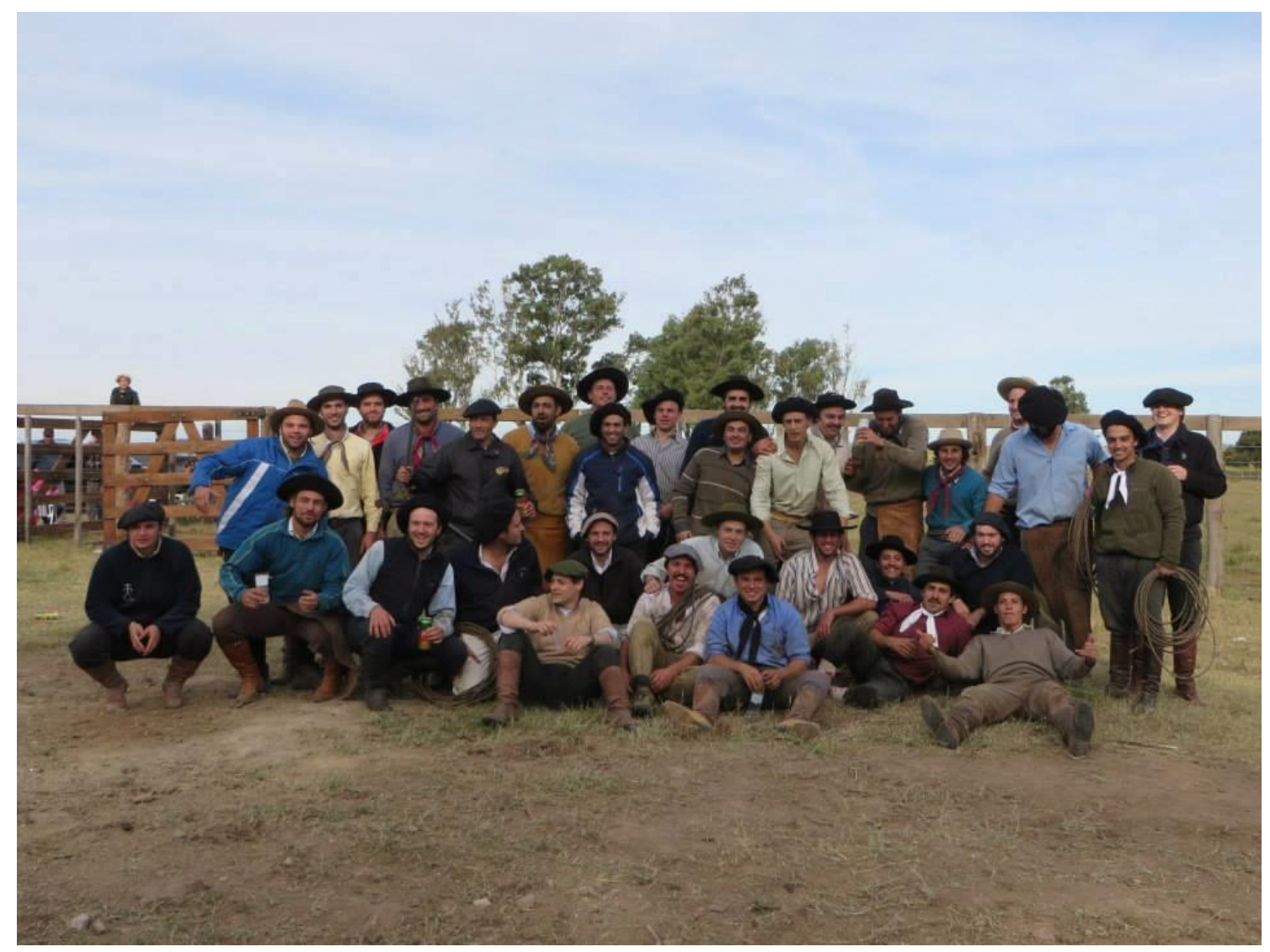

Imagem 16: Guris após marcação. 


\section{Referências:}

LEIRIS, Michel. Espelho da tauromaquia. São Paulo: Cosac Naify, 2002.

MAROCCO, Inês. Aspectos da cultura gaúcha e sua teatralidade. S/d. Disponível em http://astecnicascorporaisdogaucho.weebly.com/uploads/2/4/8/3/24832469/aspectos-da-culturagac3bacha-e-sua-teatralidade.pdf (acessado em 29.07.2016).

Recebido em: 15/08/2016. Aprovado em: 06/12/2016. 